Corresponding author:

klee.eric@mayo.edu

(C) 2020 Macke et al. This article is distributed under the terms of the Creative Commons Attribution-NonCommercial License, which permits reuse and redistribution, except for commercial purposes, provided that the original author and

source are credited.

Ontology terms: basal cell carcinoma; diffuse telangiectasia; hypopigmentation of the skin; numerous pigmented freckles; squamous cell carcinoma of the skin; superficial spreading melanoma

Published by Cold Spring Harbor Laboratory Press

doi:10.1101/mcs.a005165

\section{A novel missense variant and multiexon deletion causing a delayed presentation of xeroderma pigmentosum, group C}

\author{
Erica L. Macke, ${ }^{1,2}$ Joel A. Morales-Rosado, ${ }^{1,2}$ Aditi Gupta, ${ }^{1,2}$ Christopher T. \\ Schmitz, ${ }^{1}$ Teresa Kruisselbrink, ${ }^{3}$ Brendan Lanpher, ${ }^{1,3}$ and Eric W. Klee ${ }^{1,2,3}$ \\ ${ }^{1}$ Center for Individualized Medicine, ${ }^{2}$ Department of Health Sciences Research, ${ }^{3}$ Department of Clinical \\ Genomics, Mayo Clinic, Rochester, Minnesota 55905, USA
}

\begin{abstract}
Pathogenic variants in the XPC complex subunit, DNA damage recognition, and repair factor (XPC) are the cause of xeroderma pigmentosum, group C (MIM: 278720). Xeroderma pigmentosum is an inherited condition characterized by hypersensitivity to ultraviolet (UV) irradiation and increased risk of skin cancer due to a defect in nucleotide excision repair (NER). Here we describe an individual with a novel missense variant and deletion of exons 14-15 in XPC presenting with a history of recurrent melanomas. The proband is a 39-yr-old female evaluated through the Mayo Clinic Department of Clinical Genomics. Prior to age 36, she had more than 60 skin biopsies that showed dysplastic nevi, many of which had atypia. At age 36 she presented with her first melanoma in situ, and since then has had more than 10 melanomas. The proband underwent research whole-exome sequencing (WES) through the Mayo Clinic's Center for Individualized Medicine and a novel heterozygous variant of uncertain significance (VUS) in XPC (c.1709T > G, p.Val570Gly) was identified. Clinical confirmation pursued via XPC gene sequencing and deletion/duplication analysis of XPC revealed a pathogenic heterozygous deletion of $\sim 1 \mathrm{~kb}$ within XPC, including exons 14 and 15. Research studies determined the alterations to be in trans. Although variants in XPC generally result in early-onset skin cancer in childhood, the proband is atypical in that she did not present with her first melanoma until age 36. Review of the patient's clinical, pathological, and genetic findings points to a diagnosis of delayed presentation of xeroderma pigmentosum.
\end{abstract}

[Supplemental material is available for this article.]

\section{CASE PRESENTATION}

\section{Clinical Presentation}

The proband is a 39-yr-old Caucasian female evaluated through the Mayo Clinic Department of Clinical Genomics for a history of multiple melanomas. Prior to age 36, she had 60-70 skin biopsies that have shown dysplastic nevi, many of which had atypia that required further wide excision. At age 36, she presented with her first melanoma in situ, and since then has had more than 10 melanomas in situ, including one on her left thigh with a Breslow depth of $0.4 \mathrm{~mm}$, which was removed via wide excision. Prior to her presentation, she had no basal cell or squamous cell carcinoma. She reports no unusual sun sensitivity and has always tanned unusually quickly. She spent a typical amount of time in the sun as a teenager. As an adult, her 
A

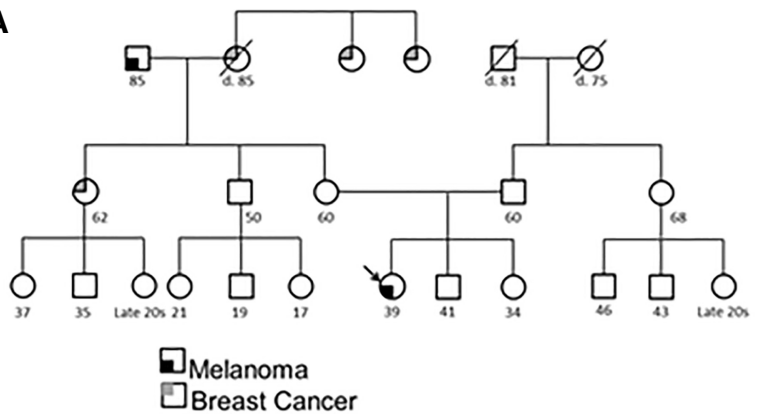

B
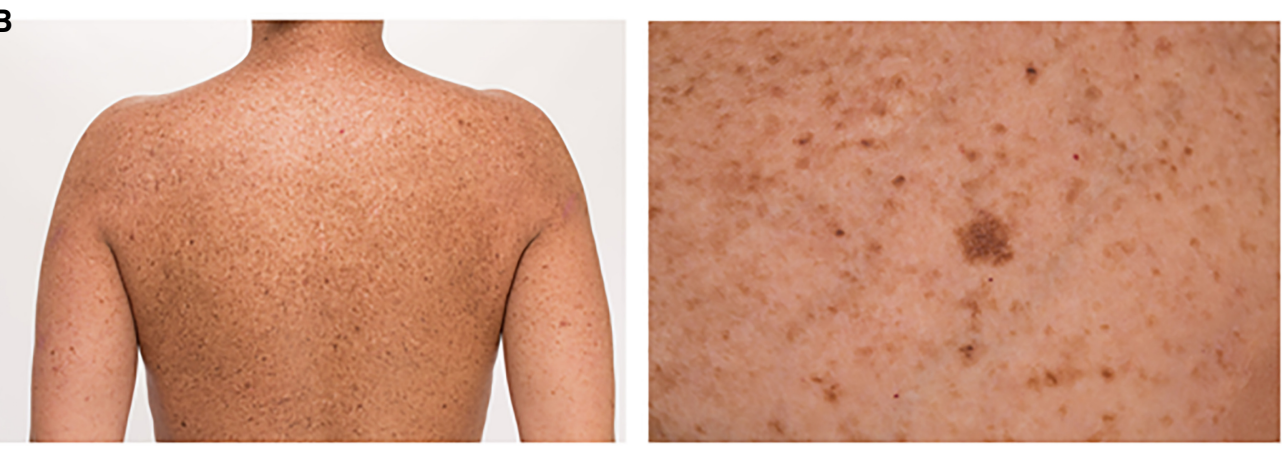

Figure 1. (A) Family pedigree for the analyzed proband by research whole-exome sequencing (WES). The proband is indicated with a black arrow. Numbers underneath indicate years of age. (B) The clinical features of the proband. Extensive freckling is observed covering the proband's entire body (left). A detailed image of the proband's skin (right).

occupation required moderate sun exposure. The proband reported that her skin as a 1-yr-old appeared clear, but by the age of 4 she was completely covered in freckles. Upon full skin exam, it was noted that her entire body, with the exception of small areas of her feet and ankles, is covered with confluent and overlapping lentiginous macules (Fig. 1B). She has a number of suspicious lesions within that background. Freckling is present on armpits all the way up into the axillary vault as well as her inguinal folds. Her palms and soles are clear. Current sun protection measures include daily use of an SPF 100 sun protectant, and she keeps herself covered as much as possible. She has no known neurological or ophthalmological abnormalities. The proband's phenotypic features are detailed in Table 1.

\begin{tabular}{lc}
\hline Table 1. Clinical findings & \\
\hline Xeroderma pigmentosum, group C clinical features $^{a}$ & Proband \\
\hline Photophobia & No \\
Skin photosensitivity & No \\
Early onset skin cancer (basal cell, squamous cell, and malignant melanoma) & Yes \\
Early freckle-like lesions in exposed areas & Yes \\
Skin atrophy & No \\
Telangiectasia & Yes \\
Actinic keratoses & No \\
Hypopigmentation & Yes \\
\hline
\end{tabular}

${ }^{a}$ The list of clinical features are based on the OMIM clinical synopsis (\#278720). 
COLD SPRING HARBOR Molecular Case Studies
Novel variant in a delayed presentation of XPC

\section{Family History}

Family members are not affected with similar freckling. She has two siblings who are unaffected. The proband's maternal grandfather had one occurrence of melanoma removed at age 44 and a second occurrence at age 88 (Fig. 1A). Interestingly, there is a very strong family history of breast cancer including her maternal aunt, maternal grandmother, maternal greatgrandmother, and maternal great-aunts (Fig. 1A). No pathogenic variants relating to inherited breast cancer were identified in the proband during raw data manual review.

\section{TECHNICAL ANALYSIS}

\section{Study Subjects and Sample Procurement}

The proband was referred to Mayo Clinic's Center for Individualized Medicine in order to seek genetic diagnosis of her recurrent melanomas. The proband underwent genetic counseling, and a full case history and family pedigree were constructed (Fig. 1A). The proband provided written consent for genetic testing. Blood samples were collected clinically from the proband, and DNA was isolated from blood samples using an Autopure LS automated DNA purifier (QIAGEN) following the manufacturer's instructions.

\section{Whole-Exome Sequencing and Variant Calling}

Whole-exome sequencing (WES) was performed at the Mayo Clinic Medical Genome Facility on genomic DNA extracted from the proband. Parental samples were not available. The exome was captured utilizing the SureSelect Human All Exon V5+UTR kit from Agilent Technologies. Sequencing was performed on an Illumina HiSeq 4000, with paired-end 101 base reads aligned to a modified human reference genome (GRCh37/hg19) using Novoalign (Novocraft Technologies). Coverage is detailed in Supplemental Table A. Sequencing quality was evaluated using FastQC (www.bioinformatics.babraham.ac.uk/ projects/fastqc/). All germline variants were jointly called through GATK Haplotype Caller and followed by PhaseByTransmission to get phasing information (McKenna et al. 2010). Each variant was annotated using the BioR Toolkit (Kocher et al. 2014) and subsequently evaluated for clinical relevance by a multidisciplinary team of clinicians and researchers with expertise in genetics, genomics, and bioinformatics.

\section{XPC Gene Sequencing with CNV Detection}

Sequencing of the XPC gene was performed by Prevention Genetics using next-generation sequencing (NGS) and Sanger sequencing technologies to cover the full coding regions of the gene of interest, plus $\sim 10$ bases of noncoding DNA flanking each exon. For NGS, patient DNA corresponding to these regions was captured using an optimized set of DNA hybridization probes. Captured DNA was sequenced using Illumina's Reversible Dye Terminator (RDT) platform (lllumina). Regions with insufficient coverage by NGS were covered by Sanger sequencing.

For Sanger sequencing, polymerase chain reaction (PCR) was used to amplify targeted regions. After purification of the PCR products, cycle sequencing was carried out using the ABI Big Dye Terminator v3.1 kit. PCR products were resolved by electrophoresis on an $A B|3730 x|$ capillary sequencer. Cycle sequencing was performed separately in both the forward and reverse directions.

\section{Deletion/Duplication Analysis}

Deletion/duplication analysis was performed by Prevention Genetics. Prevention Genetics high-density gene-centric (HDGC) array comparative genomic hybridization (aCGH) enables 
COLD SPRING HARBOR Molecular Case Studies
Novel variant in a delayed presentation of XPC the detection of deletions and duplications of single and multiple exons within a given gene (Tayeh et al. 2009). Equal amounts of genomic DNA from the patient and a sex-matched reference sample were amplified and labeled with Cy3 and Cy5 dyes, respectively. To prevent any sample cross contamination, a unique sample tracking control was added into each patient sample. Each labeled patient product was then purified, quantified, and combined with the same amount of reference product. The combined sample was loaded onto the designed array containing probes across the XPC gene and hybridized for $22-42 \mathrm{~h}$ at $65^{\circ} \mathrm{C}$. Arrays were then washed and scanned immediately at $2.5 \mu \mathrm{M}$ resolution.

\section{Phase Resolution}

The phase of the variants was determined in a research laboratory. Forward primers targeted upstream of the c.1709T > G missense variant and reverse primers downstream from the deletion in exon 16. The primer oligos were obtained from Integrated DNA Technologies and their sequences are as follows:

XPC-F1: gaggtgttctgtgagcaggag

XPC-F2: aagaaaatgtgcagcgatgg

XPC-R1: ttctgcttttcttcatcttctcg

XPC-R2: acagctgctcaaatgggaac.

We synthesized cDNA from the proband's RNA using SuperScript II Reverse Transcriptase (ThermoFisher Scientific). DNA amplification was performed by PCR using MyTaq DNA Polymerase and MyTaq Red Mix (Bioline). PCR products were visualized by agarose gel electrophoresis, and the two gel bands were separately excised, in which the smaller size product indicated a 184-bp deletion of exons 14 and 15 (Supplemental Fig. 1A). Each PCR fragment was purified using the QIAEX II Gel Extraction Kit (QIAGEN) and quantified via NanoDrop. The purified products were prepped at $4 \mathrm{ng} / \mu \mathrm{L}$ and sent to GeneWiz for Sanger Sequencing. Sequencing results demonstrated that the exon 9 SNP c.1709T $>$ G is only present in the larger PCR product and not the smaller product that contains the deletion of exons 14 and 15 (Supplemental Fig. 1B,C); thus, these variants are in trans.

\section{VARIANT INTERPRETATION}

Xeroderma pigmentosum (XP) is a rare group of autosomal recessive disorders characterized by impaired nucleotide excision repair (NER) activity and hypersensitivity to UV rays. XP is a genetically heterogeneous disorder, with eight different complementation groups (XP-A to $G$, and XP variant). Individuals with pathogenic variants in XPC have a distinct milder phenotype on the basis of cellular sensitivity assays and lack of neurological abnormalities, but they are particularly prone to malignant melanoma (Lynch 1984; Li et al. 1993; Fassihi et al. 2016). The proband is heterozygous for an $\sim 1.04-\mathrm{kb}$ deletion within XPC (Table 2). The minimum deletion boundary as determined via aCGH is Chr 3: 14,188,489-14,189,526. This includes exons 14-15, with breakpoints in introns 13 and 15. This variant is expected to result in an out-of-frame product (p.Thr808Valfs*48) predicted to undergo nonsense mediated decay (NMDEscPredictor) with the new splicing of exon 13 into 16. A similar exon 14 and 15 deletion has been previously reported in an individual with xeroderma pigmentosum (Fassihi et al. 2016). Loss-of-function variation is a known mechanism of disease, and as a result this variant is classified as pathogenic.

A heterozygous missense variant, p.Val570Gly, was also identified in XPC (Table 2). This variant falls in exon 9 of 16; a critical exon of XPC. c. 1709T > G is a novel alteration not observed in population databases (gnomAD, v2.1.1) (Lek et al. 2016) and is present in a highly 
Table 2. Genomic findings

\begin{tabular}{|c|c|c|c|c|c|c|}
\hline Gene & Genomic location & $\begin{array}{l}\text { Variant } \\
\text { type }\end{array}$ & $\begin{array}{l}\text { HGVS cDNA } \\
\text { (NM_004628.4) }\end{array}$ & HGVS protein & Zygosity & $\begin{array}{c}\text { ACMG } \\
\text { classification }\end{array}$ \\
\hline \multirow[t]{2}{*}{$X P C$} & Chr 3:14199674A > C (GRCh37) & SNV & c. $1709 T>$ G & p.Val570Gly & Heterozygous & $\begin{array}{l}\text { Likely } \\
\text { pathogenic }\end{array}$ \\
\hline & $\begin{array}{l}\text { Chr 3:14188489-14189526del Exact } \\
\text { coordinates unknown. Minimum } \\
\text { deletion boundary. (GRCh37) }\end{array}$ & Deletion & $\begin{array}{l}\text { c.2421_2604del Exon } \\
14 \text { and } 15\end{array}$ & $\begin{array}{l}\text { p.Thr808Val } \\
\text { fs*48 }\end{array}$ & Heterozygous & Pathogenic \\
\hline
\end{tabular}

(HGVS) Human Genome Variation Society, (ACMG) American College of Medical Genetics and Genomics, (SNV) single-nucleotide variation.

conserved nucleotide. In silico tools (SIFT/MutationTaster/PolyPhen-2/PredictSNP2/MCAP) predict this missense change to be deleterious (see Supplemental Material, Table B; Adzhubei et al. 2010; Lubeck et al. 2012; Vaser et al. 2015; Bendl et al. 2016; Jagadeesh et al. 2016). Residue 570 is highly conserved across mammals (see Supplemental Material, Table C) and lies in the transglutaminase-like domain (496-637aa) involved in interactions with RAD23B (Bunick et al. 2006). The interaction of XPC-RAD23B enables recognition of DNA damaged areas and initiates the assembly of the NER complex (Bunick et al. 2006; Bergink et al. 2012). Parental samples were not available to phase the heterozygous deletion and missense variant, so phase was determined via amplification of the proband's CDNA spanning both variants. Research confirmation of the two exon deletion and missense variant in different alleles was confirmed. This finding has important curation/clinical consequences as it leads to reclassification of c.1709T > G VUS as a likely pathogenic variant (Richards et al. 2015).

Although c.1709T > G has not been descried in the literature or population databases, other missense variants in XPC have been reported in individuals with similar clinical features, including late-onset XP manifestations (Chavanne et al. 2000; Bernardes de Jesus et al. 2008; Meneses et al. 2015; Fassihi et al. 2016). Fassihi et al. describe a patient with a homozygous missense variant ( $p$. Tyr585Cys) in XPC who did not develop their first melanoma until age 28, and who displayed almost no pigmentary changes. Functional testing of UV-induced DNA repair synthesis (UDS) in his skin fibroblasts was 40\% of normal after a UVR dose of $10 \mathrm{Jm}-2$ suggesting that the XPC protein was partially functional, demonstrating the pathogenicity of the observed missense variants (Fassihi et al. 2016). Additionally, Meneses et al. (2015) also observed late-onset xeroderma pigmentosum in an individual heterozygous for a missense variant ( $p$.Thr738Ala) and a frameshift variant (p.Leu763Cysfs*4). These data suggest that hypomorphic alleles can lead to an atypical late-onset presentation of $X P$, group $C$.

\section{SUMMARY}

Clinical whole-exome sequencing (WES) has a reported diagnostic rate of 25\%-30\% (Yang et al. 2013; Lazaridis et al. 2016; Retterer et al. 2016; Reuter et al. 2019). Here we used research-based WES followed by clinical confirmation of the variants to diagnose a proband presenting with a history of multiple melanomas. We describe a pathogenic deletion of exons 14 and 15 and a novel missense variant in XPC. Phasing studies demonstrated the variants were in trans and led to the reclassification of the missense VUS variant as likely pathogenic. To date, more than 100 pathogenic variants have been reported in XPC. Of these, 36\% are small deletions, 22\% are nonsense, and 14\% are splicing-related (Human Genome Mutation Database). Missense variants and gross deletions, as described here, are less common at $8 \%$ and $6 \%$, respectively. Individuals in the XP-C complementation 
$8^{\infty} \mathrm{C}$ C OLD SPRING HARBOR Molecular Case Studies
Novel variant in a delayed presentation of XPC
Competing Interest Statement The authors have declared no competing interest.

Referees

Serena Nik-Zainal

Anonymous

Received January 13, 2020; accepted in revised form April 23, 2020 group typically present with skin cancer even earlier than other subtypes (Bradford et al. 2011). Variants in XPC generally result in early onset skin cancer in childhood-the median age of onset for nonmelanoma skin cancer in xeroderma pigmentosum patients of all subtypes is $9 \mathrm{yr}$ of age, and median age of first melanoma is $22 \mathrm{yr}$. This reported proband is atypical in that she did not present with her first melanoma until age 36 and had no prior basal or squamous cell carcinomas. Review of the patient's clinical, pathological, and genetic findings points to a diagnosis of delayed presentation of xeroderma pigmentosum potentially driven by a hypomorphic missense allele.

\section{ADDITIONAL INFORMATION}

\section{Database Deposition and Access}

Variants have been submitted to ClinVar (https://www.ncbi.nlm.nih.gov/clinvar/) and can be found under accession numbers SCV001194325.1 and SCV001194326.1.

\section{Ethics Statement}

This study was approved by the Mayo Clinic institutional review board and all participants provided written informed consent for genetic testing. The patient provided written consent for publication of identifiable images.

\section{Acknowledgments}

The authors thank the patient for participating in this study

\section{Author Contributions}

E.L.M., J.A.M.-R., and E.W.K. analyzed patient variants and wrote the manuscript. A.G. analyzed patient variants. T.K. and B.L. oversaw patient care and genetic interpretation. C.T.S. performed experiments to determine phase.

\section{Funding}

This study was supported by the Mayo Clinic Center for Individualized Medicine (CIM), the Investigative and Functional Genomics Program, and the William O. Lund, Jr. and Natalie C. Lund Charitable Foundation.

\section{REFERENCES}

Adzhubei IA, Schmidt S, Peshkin L, Ramensky VE, Gerasimova A, Bork P, Kondrashov AS, Sunyaev SR. 2010. A method and server for predicting damaging missense mutations. Nat Methods 7: 248-249. doi:10.1038/ nmeth0410-248.

Bendl J, Musil M, Štourač J, Zendulka J, Damborský J, Brezovský J. 2016. PredictSNP2: a unified platform for accurately evaluating SNP effects by exploiting the different characteristics of variants in distinct genomic regions. PLoS Comput Biol 12: e1004962. doi:10.1371/journal.pcbi.1004962.

Bergink S, Toussaint W, Luijsterburg MS, Dinant C, Alekseev S, Hoeijmakers JH, Dantuma NP, Houtsmuller AB, Vermeulen W. 2012. Recognition of DNA damage by XPC coincides with disruption of the XPC-RAD23 complex. J Cell Biol 196: 681-688. doi:10.1083/jcb.201107050.

Bernardes de Jesus BM, Bjørås M, Coin F, Egly JM. 2008. Dissection of the molecular defects caused by pathogenic mutations in the DNA repair factor XPC. Mol Cell Biol 28: 7225-7235. doi:10.1128/MCB.00781-08.

Bradford PT, Goldstein AM, Tamura D, Khan SG, Ueda T, Boyle J, Oh KS, Imoto K, Inui H, Moriwaki S, et al. 2011. Cancer and neurologic degeneration in xeroderma pigmentosum: long term follow-up characterises the role of DNA repair. J Med Genet 48: 168-176. doi:10.1136/jmg.2010.083022. 
Bunick CG, Miller MR, Fuller BE, Fanning E, Chazin WJ. 2006. Biochemical and structural domain analysis of xeroderma pigmentosum complementation group C protein. Biochemistry 45: 14965-14979. doi:10 .1021/bi061370o.

Chavanne F, Broughton BC, Pietra D, Nardo T, Browitt A, Lehmann AR, Stefanini M. 2000. Mutations in the $X P C$ gene in families with xeroderma pigmentosum and consequences at the cell, protein, and transcript levels. Cancer Res 60: 1974-1982.

Fassihi H, Sethi M, Fawcett H, Wing J, Chandler N, Mohammed S, Craythorne E, Morley AM, Lim R, Turner S, et al. 2016. Deep phenotyping of 89 xeroderma pigmentosum patients reveals unexpected heterogeneity dependent on the precise molecular defect. Proc Natl Acad Sci 113: E1236-E1245. doi:10.1073/pnas 1519444113 .

Jagadeesh KA, Wenger AM, Berger MJ, Guturu H, Stenson PD, Cooper DN, Bernstein JA, Bejerano G. 2016. $\mathrm{M}-\mathrm{CAP}$ eliminates a majority of variants of uncertain significance in clinical exomes at high sensitivity. Nat Genet 48: 1581-1586. doi:10.1038/ng.3703.

Kocher JP, Quest DJ, Duffy P, Meiners MA, Moore RM, Rider D, Hossain A, Hart SN, Dinu V. 2014. The Biological Reference Repository (BioR): a rapid and flexible system for genomics annotation. Bioinformatics 30: 1920-1922. doi:10.1093/bioinformatics/btu137

Lazaridis KN, Schahl KA, Cousin MA, Babovic-Vuksanovic D, Riegert-Johnson DL, Gavrilova RH, McAllister TM, Lindor NM, Abraham RS, Ackerman MJ, et al. 2016. Outcome of whole exome sequencing for diagnostic odyssey cases of an individualized medicine clinic: the Mayo Clinic experience. Mayo Clin Proc 91: 297307. doi:10.1016/j.mayocp.2015.12.018.

Lek M, Karczewski KJ, Minikel EV, Samocha KE, Banks E, Fennell T, O’Donnell-Luria AH, Ware JS, Hill AJ, Cummings BB, et al. 2016. Analysis of protein-coding genetic variation in 60,706 humans. Nature 536: 285-291. doi:10.1038/nature19057.

Li L, Bales ES, Peterson CA, Legerski RJ. 1993. Characterization of molecular defects in xeroderma pigmentosum group C. Nat Genet 5: 413-417. doi:10.1038/ng1293-413.

Lubeck E, Coskun AF, Zhiyentayev T, Ahmad M, Cai L. 2012. MutationTaster2: mutation prediction for the deep-sequencing age. Nat Methods 9: 743-748. doi:10.1038/nmeth.2892.

Lynch HT. 1984. Xeroderma pigmentosum. Complementation group C and malignant melanoma. Arch Dermatol 120: 175-179. doi:10.1001/archderm.120.2.175.

McKenna A, Hanna M, Banks E, Sivachenko A, Cibulskis K, Kernytsky A, Garimella K, Altshuler D, Gabriel S, Daly M, et al. 2010. The Genome Analysis Toolkit: a MapReduce framework for analyzing next-generation DNA sequencing data. Genome Res 20: 1297-1303. doi:10.1101/gr107524.110

Meneses M, Chavez-Bourgeois M, Badenas C, Villablanca S, Aguilera P, Bennàssar A, Alos L, Puig S, Malvehy J, Carrera C. 2015. Atypical clinical presentation of xeroderma pigmentosum in a patient harboring a novel missense mutation in the XPC gene: the importance of clinical suspicion. Dermatology 231: 217-221. doi:10.1159/000433527.

Retterer K, Juusola J, Cho MT, Vitazka P, Millan F, Gibellini F, Vertino-Bell A, Smaoui N, Neidich J, Monaghan KG, et al. 2016. Clinical application of whole-exome sequencing across clinical indications. Genet Med 18: 696-704. doi:10.1038/gim.2015.148.

Reuter CM, Kohler JN, Bonner D, Zastrow D, Fernandez L, Dries A, Marwaha S, Davidson J, Brokamp E, Herzog $\mathrm{M}$, et al. 2019. Yield of whole exome sequencing in undiagnosed patients facing insurance coverage barriers to genetic testing. J Genet Couns 28: 1107-1118. doi:10.1002/jgc4.1161.

Richards S, Aziz N, Bale S, Bick D, Das S, Gastier-Foster J, Grody WW, Hegde M, Lyon E, Spector E, et al. 2015. Standards and guidelines for the interpretation of sequence variants: a joint consensus recommendation of the American College of Medical Genetics and Genomics and the Association for Molecular Pathology. Genet Med 17: 405-424. doi:10.1038/gim.2015.30

Tayeh MK, Chin ELH, Miller VR, Bean LJH, Coffee B, Hegde M. 2009. Targeted comparative genomic hybridization array for the detection of single- and multiexon gene deletions and duplications. Genet Med 11: 232-240. doi:10.1097/GIM.0b013e318195e191.

Vaser R, Adusumalli S, Ngak Leng S, Sikic M, Ng PC. 2015. SIFT missense predictions for genomes. Nat Protoc 11: 1-9. doi:10.1038/nprot.2015.123.

Yang Y, Muzny DM, Reid JG, Bainbridge MN, Willis A, Ward PA, Braxton A, Beuten J, Xia F, Niu Z, et al. 2013. Clinical whole-exome sequencing for the diagnosis of Mendelian disorders. N Engl J Med 369: 15021511. doi:10.1056/NEJMoa1306555. 


\section{COLD SPRING HARBOR Molecular Case Studies}

\section{A novel missense variant and multiexon deletion causing a delayed presentation of xeroderma pigmentosum, group $\mathbf{C}$}

Erica L. Macke, Joel A. Morales-Rosado, Aditi Gupta, et al.

Cold Spring Harb Mol Case Stud 2020, 6: a005165

Access the most recent version at doi: $10.1101 / \mathrm{mcs} . a 005165$
Supplementary http://molecularcasestudies.cshlp.org/content/suppl/2020/08/25/mcs.a005165.D Material C1
References This article cites 23 articles, 6 of which can be accessed free at: http://molecularcasestudies.cshlp.org/content/6/4/a005165.full.html\#ref-list-1
License This article is distributed under the terms of the Creative Commons Attribution-NonCommercial License, which permits reuse and redistribution, except for commercial purposes, provided that the original author and source are credited.
Email Alerting Receive free email alerts when new articles cite this article - sign up in the box at the Service top right corner of the article or click here.

